\title{
PAISAGEM RECUPERADA - O PROJETO DE QUALIFICAÇÃO DA PRAÇA NOSSA SENHORA DA LUZ EM SALVADOR-BA
}

\author{
RECUPERATED LANDSCAPE - QUALIFY DESIGN FOR "NOSSA SENHORA DA LUZ" SQUARE \\ IN SALVADOR-BA
}

\author{
GUIMARÃES, Caroline Pedreira \\ Arquiteta (FAUFBA), Programa de Mestrado em Engenharia Ambiental Urbana da EP-UFBA. \\ E-mail: carolinepg1@hotmail.com
}

\section{CUNHA, Rita Dione Araújo}

Engenheira, professora doutora do Departamento de Tecnologia Aplicada à Arquitetura da Faculdade de Arquitetura, Universidade Federal da Bahia.

E-mail: ritadi@uol.com.br

\section{RESUMO}

Hoje em dia os espaços públicos abertos possuem um novo papel como lugares de convívio e como composição da paisagem urbana. Existe uma tendência mundial em se resgatar a importância dos espaços públicos abertos enquanto paisagens construídas, levando em conta o cidadão que os utiliza. Estratégias de remodelação dos espaços públicos têm sido implementadas em todo o mundo, inclusive no Brasil, introduzindo o conceito de "cidade recuperada" e ampliando-o para o de "paisagem recuperada". Esse trabalho visa ressaltar a importância do paisagismo desses espaços livres públicos, tomando como exemplo a revitalização da praça Nossa Senhora da Luz, no bairro da Pituba, em Salvador-BA, que se encontrava, até bem pouco tempo, em estado de abandono e sem qualidade ambiental satisfatória para o usuário. Buscase neste artigo relacionar a importância do projeto da paisagem para o usuário da praça pelo qual a mesma ganha uma nova dimensão no contexto urbano recuperando sua importância quanto paisagem construída.

Palavras-chave: Espaço público, paisagem construída, requalificação do espaço público.

\begin{abstract}
Nowadays open public spaces have played much more intensively as life place and as urban landscape. There is a world tendency to catch the great importance of open public spaces as building landscapes also not forgetting the users of these places. Open spaces remodeling strategies has been implemented in al world, including Brazil, using the "recuperated city" new concept that is amplified to "recuperated landscape". This work aims to reinforce the importance of open public spaces landscape and discusses an example of square in Pituba District of Salvador-BA. This square like many others in Salvador had lost environmental quality in less than four decades and had become an abandoned space almost without use. This work wants to related landscape design to users showing how to recuperate landscape in urban context.
\end{abstract}

Key words: Public space, square, open space.

\section{Introdução}

O espaço livre público sempre foi lugar de encontro comércio e circulação, embora no decorrer da história os padrões de uso tenham variado, conforme a evolução da sociedade e as diferenças dos lugares onde se desenvolveram as cidades. O século XX e o atual foram responsáveis por mudanças radicais nas condições para esses três usos principais do espaço livre público. Basicamente o espaço que antes era do pedestre foi usurpado pelo automóvel e os padrões de ocupação do espaço urbano foram se modificando em função do aparecimento de avenidas e da verticalização da cidade através de grandes edifícios, fazendo com que praças antigas 
perdessem a identidade com o entorno urbano ou fazendo aparecer novos tipos de espaços públicos e novas formas de relacionamento dos habitantes da cidade com o espaço urbano.

Muitas praças e espaços públicos utilizados pelo cidadão perderam seu valor paisagística seja pela modificação das suas funções originais ou por algum processo de degradação contínua pela perda de identidade com o entorno imediato também modificado com o passar dos anos. O conceito de "cidade recuperada" ampliado para "paisagem recuperada" vem justamente demonstrar os esforços feitos para resgatar o equilíbrio entre os usos da cidade como lugar de encontro, comércio e circulação e isto pode ser feito através da recuperação e "requalificação" dos espaços livres públicos já existentes.

Nascido na Europa, segundo Guehl e Gemzoe (2002) o conceito de cidade recuperada se reforça na tendência mundial de remodelação dos espaços livres públicos dos grandes centros urbanos em vários países. O Brasil também adota essa tendência na medida da necessidade que suas grandes cidades apresentam em dar vida a espaços esquecidos, degradados ou pouco usados em virtude de processos de rápidas ou drásticas transformações urbanas, como forma de restaurar o equilíbrio da paisagem e da vida da cidade.

O projeto arquitetônico aparece como fator de destaque para concretizar a recuperação desses espaços públicos e da paisagem como um todo. A análise das áreas públicas inclui o seu planejamento, uma vez que devem ser consideradas como constantes objetos de intervenção, projeto ou desenho. $O$ projeto arquitetônico no caso dos espaços públicos é fundamental na busca pelo resultado da adequação social do meio físico às necessidades humanas e conseqüentemente o resultado da integração do homem com a paisagem que o cerca. É através do projeto arquitetônico que o conceito de "recuperação do espaço urbano" pode ser ampliado para "recuperação da paisagem" dentro da tendência atual.

Como várias cidades brasileiras, Salvador passou por grandes mudanças como reflexo do seu processo de crescimento. Como conseqüência, muitos de seus espaços públicos perderam a qualidade ambiental e a função social que partilhavam com os demais espaços da cidade, passando a necessitar de urgentes programas de recuperação para tornar a se relacionar com a paisagem urbana e se tornar novamente espaços sociais.

Esse artigo é resultado da investigação da origem até os dias atuais da praça Nossa Senhora da Luz no bairro da Pituba em Salvador-BA e visa ressaltar a importância dos espaços livres públicos para os grandes centros urbanos, tomando como exemplo o processo de revitalização da paisagem através do projeto de qualificação da praça. Para tanto, faz-se uma abordagem da sua evolução no contexto urbano, mostrando a importância do seu projeto de reforma.

Antiga área de fazenda, o bairro da Pituba teve o seu primeiro loteamento projetado, em 1919 e, nas décadas de 1950 e 1960, o que era zona de veraneio foi se transformando em um dos bairros mais importantes da cidade de Salvador. A praça Nossa Senhora da Luz, cujo elemento principal é a igreja de mesmo nome, a partir da qual ela se formou, faz parte do bairro, desde a sua origem. Na década de 1990, entretanto, a praça que já vinha sendo há anos degradada pela falta de infra-estrutura e pela própria ação do tempo, além da decadência do entorno, acabou se tornando um local evitado pela população local, perdendo muito do seu valor como paisagem. No ano 2000, a administração municipal de Salvador decidiu que era necessário trazer de volta esse espaço para a comunidade, mas um espaço com funções e características que permitissem a apropriação do mesmo, um espaço de troca, de reunião, de festa, de contato e mesmo de contemplação.

Atualmente, a Pituba é um bairro residencial e comercial moderno. Possui algumas das principais avenidas da cidade o que gera um fluxo intenso de pessoas, além do seu contingente populacional residente. O projeto de qualificação da praça Nossa Senhora da Luz, não só devolveu ao 
bairro um pedaço da sua identidade, como também contribuiu para a melhoria da paisagem urbana e da qualidade ambiental. Pretende-se, através desse exemplo, ressaltar a importância do conceito de arquitetura da praça como espaço social urbano e como o projeto arquitetônico é fundamental para definir a "paisagem da cidade recuperada".

\section{2 - Espaços livres públicos e paisagem recuperada}

\section{1 - Vida urbana e espaços livres públicos}

Os espaços livres públicos devem ser vistos como elementos importantes na cidade, pois desempenham papéis fundamentais tais como ambientais, sociais e culturais. Essa importância se dá, conforme Cunha (2002), muito mais em termos de suas relações com o contexto urbano e às facilidades que esses espaços livres possibilitam para a manutenção das atividades urbanas do que em relação a sua quantidade dentro de uma cidade. Tais espaços constituídos por avenidas, ruas, largos, pátios, praças, parques, vielas e terrenos baldios, entre outros são relacionados com o crescimento urbano, pelas formas de controle do uso e ocupação do solo, de parcelamento e arruamento ou loteamento.

Macedo (1995) afirma que para pensar a cidade, devem ser pensados os seus espaços livres de edificação, aqueles onde flui diariamente parte de nossas vidas. Pensar os espaços públicos pode levar a novas alternativas de desenho da paisagem urbana, ou pelo menos a uma melhor forma de organização e uso dos espaços já existentes. Seria como ligar o desenho dos espaços livres de uma forma constante ao desenho da cidade, como um fator fundamental para o seu bom funcionamento.

Todo espaço da cidade deve ser objeto de uma intervenção, de um projeto, de um desenho. Nas cidades, realmente, necessita-se de áreas livres, desenhadas, tratadas e distribuídas adequadamente de modo a serem acessíveis à população como um todo. Os espaços livres de edificação devem ter uma qualificação de usos e conseqüentemente de necessidades físicas para tal uso, como iluminação, acesso, ventilação adequada, formas e volumes adequados, que devem expressos com especificações tão cuidadosas como a que se dedica ao interior dos espaços cobertos. Ou seja, a arquitetura dos espaços livres públicos é tão importante quanto a dos espaços edificados.

Embora seja um fato recorrente em muitas cidades, a falta de uso e o esvaziamento dos espaços livres públicos não são regra e acontecem em áreas urbanas onde não se tem manutenção de tais espaços ou onde não existe necessariamente a exigência de sua presença ou ainda em alguns lugares que possuem uma fraca estruturação espacial. A manutenção do espaço livre público é um dever social, mas isto não é um fato consolidado nas grandes cidades brasileiras, conforme Macedo (1998).

"Em contraste à vida urbana moderna e aos diversos espaços privados, a oportunidade das pessoas em usar seus sentidos e interagir diretamente com seu entorno vem tornando-se extremamente atrativa" (GUEHL; GEMZOE, 2002). Segundo os mesmos autores, a sociedade da informação está fornecendo novos sentidos e significados à cidade como lugar de encontro, portanto a manutenção sistemática dos espaços públicos da cidade é fator fundamental para garantir sua existência. Muitas vezes a falta de usuários está relacionada à falta de manutenção do espaço, e isso pode levar a um perigoso e repetitivo ciclo que acaba afastando os usuários. É indispensável à continuidade dos espaços livres públicos que haja o processo de manutenção. Quando bem mantidos e cuidados em todos os seus aspectos, esses espaços contemplarão todas as suas funções sociais, estéticas e ambientais, caracterizando-se como parte atraente da paisagem urbana ao usuário desses espaços, congregando e sintetizando a vida na cidade. 
Para Hardt (1998), o conceito de praça é delimitado pela arquitetura de um espaço devidamente programado, definido espacialmente por elementos construídos, com ou sem vegetação, sendo gerado pela relação entre volumes construídos e vazio que dão ao conjunto a escala humana. Essa autora salienta o conceito de praça como espaço arquitetônico ou vinculado a um projeto. Embora menos amplo do que as definições anteriores, o conceito de praça de Hardt ressalta a importância do desenho e do projeto do espaço para qualificá-lo quanto às suas funções sociais e ambientais. É a partir de um projeto que a praça ou espaço público busca responder aos anseios dos seus usuários. Através do projeto pode-se avaliar a qualidade do espaço físico em relação ao comportamento do cidadão que o utiliza.

\section{3 - A praça Nossa Senhora da Luz e o bairro da Pituba em Salvador}

\section{1 - O bairro da Pituba no processo de evolução urbana de Salvador}

A cidade de Salvador, desde a sua origem, do ponto de vista do paisagismo, sempre foi cheia de espaços públicos marcados como lugar de encontro e reunião das pessoas, lugar de troca de informações, lugar onde eventos importantes foram encenados: festas e festivais, procissões, encontros cívicos e execuções, para mencionar alguns. No entanto, no século XX, as condições para os usos principais do espaço público mudaram. Os novos padrões de tráfego, comércio e comunicação foram tão radicais que interromperam séculos de tradição na dinâmica urbana. A cidade se espalhou com grande rapidez e a dinâmica de produção dos espaços para habitação, circulação, trabalho e lazer se modificou para acompanhar o crescimento da cidade. Isso influenciou no modo de criação e nos padrões dos novos espaços públicos e conseqüentemente no conceito de espaço público para a nova cidade que emergia.

De acordo com Teixeira (1978), a evolução da cidade do Salvador, até os nossos dias, pode ser dividida em dois períodos: o primeiro, até o início do século XIX, quando o seu crescimento foi lento, incorporando pequena parte de área construída a um centro tradicional e de origem colonial, originalmente marcado por quadras reticulares e cuja escala era bastante humanizada, não havendo o automóvel ainda como elemento de mudança nos padrões e importância das ruas. Neste período, as praças como espaços públicos guardavam ainda um caráter de agregação dos habitantes da cidade. O segundo período, compreendendo o resto do século passado e o atual, quando a cidade se espalhou enormemente, ocupando uma superfície mais de dez vezes maior do que nos séculos anteriores, criando-se novos bairros, aumentando os existentes, crescimento que se deu de forma desordenada, sem nenhum controle e mais rapidamente do que as medidas administrativas postas em prática, resultando num relativo caos urbano.

Entre séculos XIX e XX, a cidade cresceu extraordinariamente, formando-se muitos bairros novos, entre eles o da Pituba, área objeto do presente estudo. Entre 1932 e 1950 foram aprovados quase 40 loteamentos de vulto oferecendo um total aproximado de 30.100 lotes - ocupando área de 540 ha espalhados por diversas áreas da cidade (entre elas o bairro da Pituba) - sem contrapartida de obras de infra-estrutura correspondente, gerando problemas que se refletem até nossos dias. Neste período, foi constituída pela primeira vez, uma comissão designada para estudar os problemas da cidade, com participação de vários organismos da sociedade, culminando com a contratação de um plano para a cidade - EPUCS em outubro de 1942.

Até 1942, o acesso à Pituba era bastante difícil, visto que se chegava pelo interior, cruzando veredas e picadas ou, mais comumente, via o Bonde de Amaralina, de onde se avistava a entrada da Fazenda Pituba com acesso rústico já construído até a praça Nossa Senhora da Luz (ANDRADE, 2003). Até o começo do século XX, a região era apenas uma localidade da costa oceânica distante do centro da cidade, que abrigava uma comunidade de pescadores. 
Em 1914, a Fazenda Pituba foi adquirida por Joventino Silva, das mãos do comerciante português Manoel Dias da Silva. Em 1919, este contrata Theodoro Sampaio, um conceituado engenheiro da cidade, para dividir a maior parte da fazenda em loteamentos e comercializá-los. Esse projeto foi concebido de maneira a oferecer o máximo de bem estar à população, pois contemplava todos os requisitos exigidos por uma demanda selecionada em função do poder aquisitivo, indicando que ali seria local de residência para uma população que poderia dar liquidez àquele empreendimento. O projeto da "Cidade Luz" que foi concebido em 1919, somente foi aprovado pela Câmera Municipal de Salvador em 1932, beneficiando o terreno onde seria implantado o loteamento "Cidade Luz", cujo nome é uma referência à antiga capela existente, cuja padroeira era a Virgem Maria sob a invocação de Nossa Senhora da Luz.

Os primeiros lotes foram adquiridos por famílias de classe média, que tinham a intenção de transformá-los em locais de veraneio, porém o acesso continuava difícil. (ADEMI-BA, 1993). O núcleo da nova ocupação era a praça Nossa Senhora da Luz, no entorno da qual estavam 52\% das construções do local, o acesso se dava através de uma ponte sobre o córrego Pituba (SAM$P A I O, 1919)$. A antiga capela se localizava antes do referido córrego, estando assim na margem oposta da atual igreja Nossa Senhora da Luz, construída em 1954 (ANDRADE, 2003).

Somente nos anos de 1960, o bairro da Pituba começava a tomar forma. A avenida Otávio Mangabeira, que liga ltapuã ao centro da cidade pela orla (e, portanto, tornava a Pituba acessível) fora aberta e pavimentada, em 1950. Em 1968, a antiga estrada Brotas-Pituba, atualmente a avenida Antonio Carlos Magalhães (mais conhecida como avenida ACM), foi asfaltada. A Avenida Paulo VI que se estende da beiramar para o interior do bairro também fora asfaltada em 1965; as demais ruas do loteamento se encontravam, nesse período, abertas, mas sem cobertura asfáltica. Ainda nesse período, o loteamento estava semi-ocupado e constituído de boas e elegantes casas, muitas com piscina e jardim, em sua grande maioria residências unidomiciliares. Existia, ainda nessa época, a igreja de Nossa Senhora da Luz (ver Figura 1), o Clube Português, ambos do final da década de 1940, uma unidade do exército (o Colégio Militar de Salvador) e um hotel e restaurante de período mais recente (BRITO, 1993).

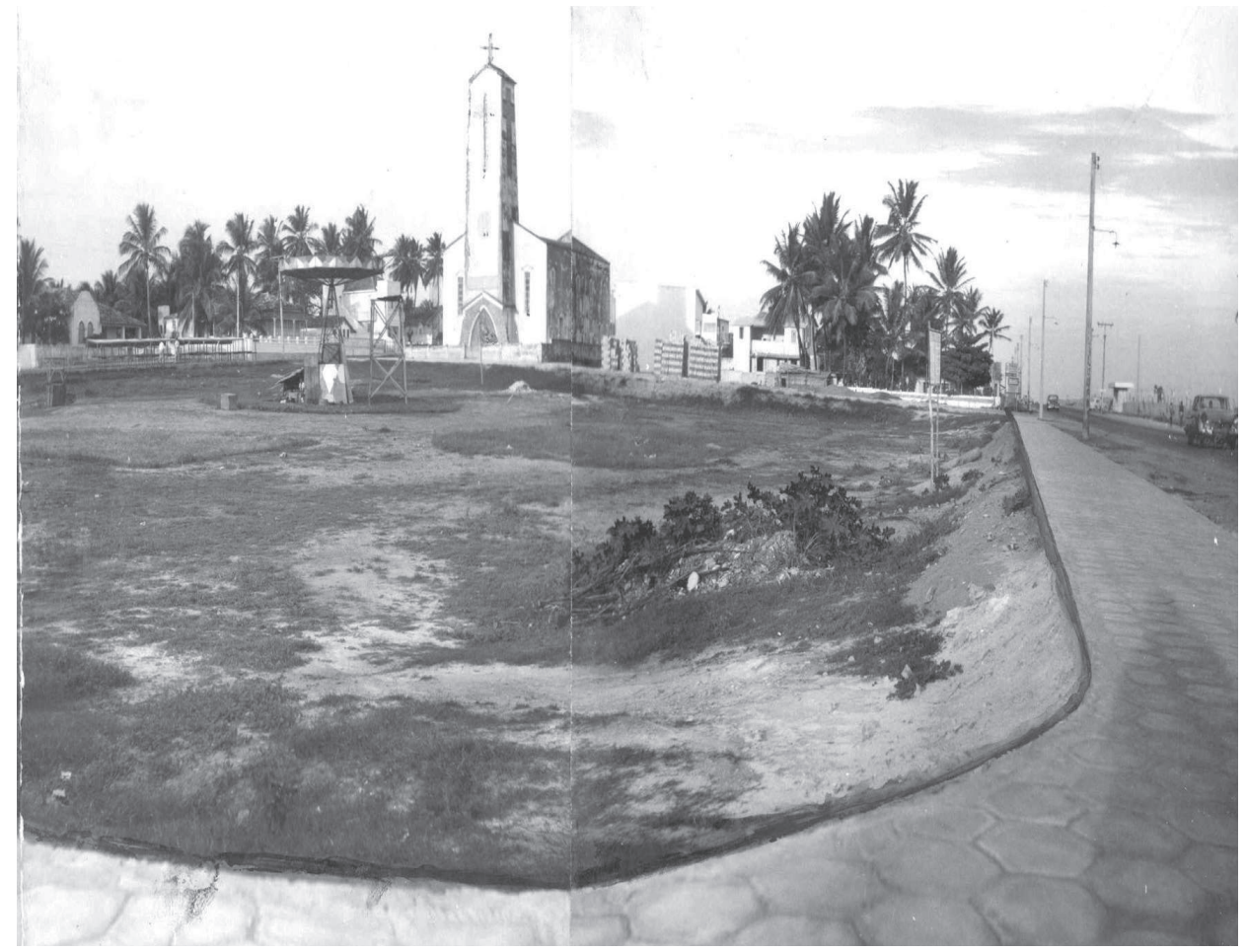

Figura 1: Vista da praça Nossa Senhora da Luz, 1966

Fonte: Jornal A Tarde (1966) 
De acordo com o Plano de Desenvolvimento Urbano de Salvador (PLANDURB, 1977), o atual bairro da Pituba começou a urbanizar-se como zona de veraneio, mediante ocupação dos lotes mais próximos à praia, dentre aqueles integrantes do pioneiro Loteamento Cidade da Luz, projetado na década de 1920 por Theodoro Sampaio e aprovado pela Prefeitura em 1932. Em décadas posteriores, afirmou-se como zona residencial, surgindo aí modernas casas de alto nível construtivo e padrão de acabamento, firmando-se como uma das alternativas à falta de oferta e aos altos preços dos terrenos nas tradicionais zonas da Cidade constituídas de bairros antigos como Vitória, Barra, Barra Avenida e Graça.

Porém, a expansão do sistema viário urbano, em especial a abertura várias avenidas de vale que facilitou o acesso direto do bairro a áreas mais antigas e tradicionais da cidade, bem como o acesso às novas áreas através dos novos vetores de expansão da cidade como a avenida Paralela fizeram com que a tendência de ocupação pela faixa abastada da população se modificasse. Além dessas avenidas que abriram a comunicação do bairro com toda a cidade, a pavimentação asfáltica de praticamente todas as ruas do bairro, a instalação da Paróquia e a construção da igreja de Nossa Senhora da Luz ajudou no processo de mudança no padrão de ocupação do bairro.

A criação do $\mathrm{BNH}$ e a conseqüente dinamização das atividades da indústria de construção civil, basicamente do seu segmento imobiliário, vieram atribuir um ritmo bastante acelerado a este processo. Inicialmente com os conjuntos residenciais horizontais que se instalaram na parte posterior do bairro. Posteriormente, foi a verticalização que se manifestou, através de conjuntos habitacionais e também por meio de edifícios isolados. Isso possibilitou o acesso à área de populações de outras faixas de renda, todas, no entanto, com relativo poder de compra - e repetindo, assim, um modelo espontâneo e típico de uma expansão urbana conduzida pelo mercado, pouco antes imposto aos bairros da Vitória, Barra, etc.

Este processo cresceu acentuadamente, a partir de 1975, quando, apesar da grande disponibilidade de terras, passou a existir a substituição tipológica do padrão unifamiliar pelos edifícios de apartamentos, dando à zona uma característica bem definida, com predominância, ora de habitaçãoes unidomiciliares, ora de edifícios de apartamentos. Simultaneamente, o crescente congestionamento do tráfego no centro e a inexistência de um plano diretor para a Cidade fizeram com que também este bairro se visse invadido por atividades terciárias, e até industriais, a maioria delas completamente desvinculadas da sua função residencial.

A criação de espaços livres públicos para o lazer neste bairro como nos tantos novos que surgiram na mesma época seguiu a tendência de se atrelar às poucas áreas que sobravam dos loteamentos para este fim. Em geral apareceram poucas pracinhas de bairro que não acompanharam as rápidas mudanças do entorno, esvaziando-se por falta de uma adequação às modificações tipológicas de ocupação do solo e por não responderem mais ao crescimento da população ao redor.

O bairro da Pituba continua, ainda hoje, como uma das áreas mais dinâmicas em termos de ritmo de crescimento, em vista da evolução do número de domicílios aí existentes. A recente recuperação e mudanças de tráfego nas suas principais avenidas de acesso acabaram por valorizar mais o bairro e aumentar a importância de se recuperar as áreas de praças degradadas. Por conta disso e de um recente programa municipal de recuperação dos espaços públicos com especial cuidado com o seu paisagismo, foram incluídas algumas praças da Pituba, entre elas a mais antiga e tradicional, qual seja, a praça Nossa Senhora da Luz.

\section{2 - Origem e a decadência da praça Nossa Senhora da Luz na década de 1990 do século $\mathrm{XX}$}

Apesar de originada a praça em 1919, o seu projeto só foi concretizado nos anos 60, sendo ladeada pelas avenidas Manoel Dias da Silva e Otávio Mangabeira, e pelas ruas Pernambuco e 
Rio de Janeiro. A área que contorna imediatamente a praça é pouco verticalizada se comparada com o restante do bairro. Os prédios que a contornavam, desde o início, possuíam em comum a pouca altura entre eles e isso permaneceu até a atualidade. Seu entorno atual é constituído de uma igreja católica, um teatro, alguns edifícios residenciais, outros comerciais.

Seu primeiro projeto era uma praça de formato retangular com pouca vegetação e com poucos equipamentos de lazer, alguns bancos, abrigando ainda a praça uma estação de tratamento de esgoto da Empresa Baiana de Águas e Saneamento - Embasa. O projeto contemplava também uma pista para skate como uma das poucas propostas de área de lazer dentro do espaço.

Até o início dos anos oitenta, a praça era tradicionalmente utilizada pela população, mas os seus usos foram se restringindo por uma crescente falta de cuidados com o equipamento urbano e por uma desqualificação crescente do entorno imediato. Apesar da presença da lgreja à sua frente como elemento polarizador da população usuária, a praça, com o passar dos anos, já não conseguia atrair as pessoas da mesma forma como no início. Não fosse pela pista de skate que atraía grupos de adolescentes para a praça, o local já não tinha mais a força de antes. Até bem pouco tempo antes da sua reforma, o seu piso encontrava-se completamente destruído, a vegetação precisando de cuidados urgentes, capim precisando ser aparado, muriçocas, odores desagradáveis e os bancos em péssimo estado de conservação, além da falta de equipamento de lazer para as crianças (como pode ser comprovado na Figura 2).

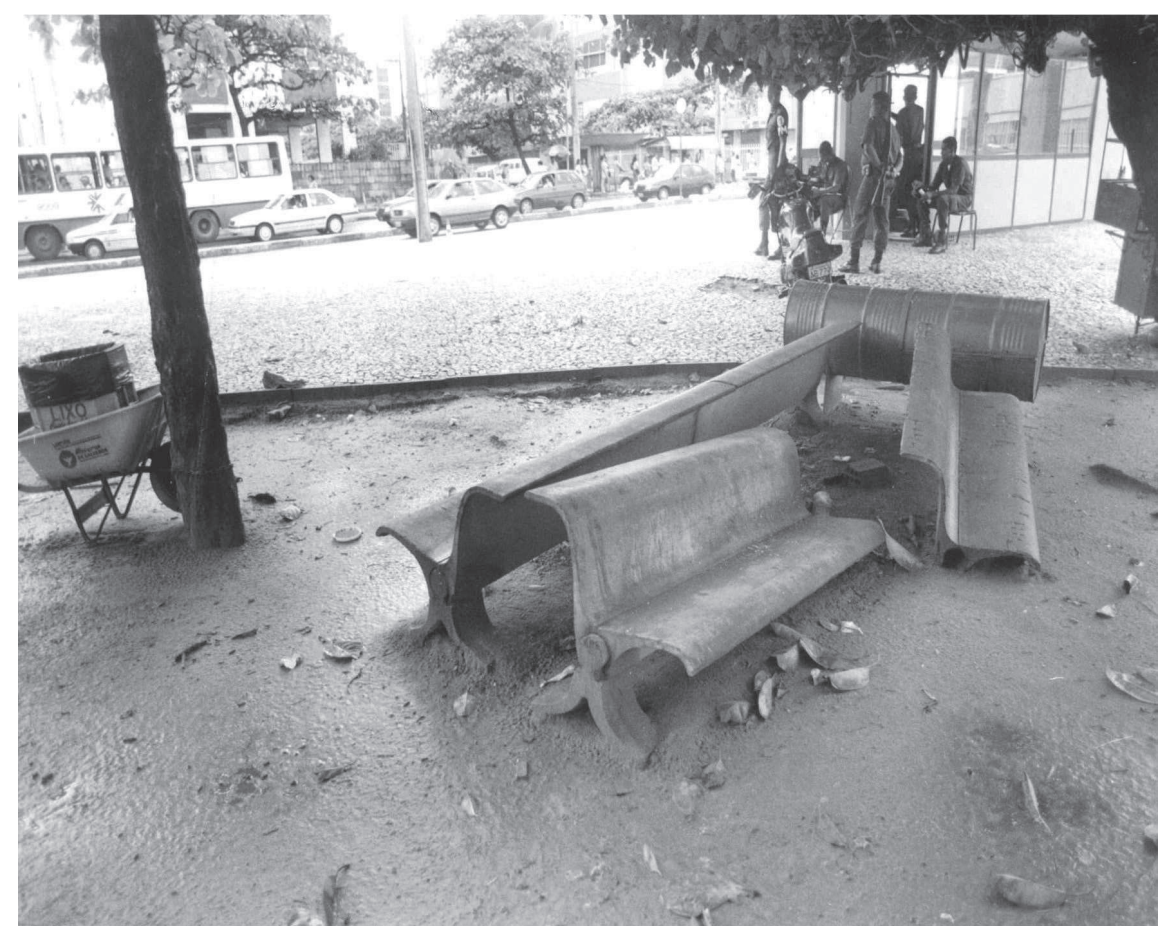

Figura 2: Vista da praça Nossa Senhora da Luz, 1995

Fonte: Jornal A Tarde (1995)

A decadência do espaço não se restringia somente à praça em si, mas a própria avenida ACM com seus graves problemas de enchentes em épocas de chuva, o Clube Português que, na década de 1990 foi abandonado e degradado, e até a lgreja que necessitava de urgentes reformas, tudo contribuía para tornar a paisagem da praça e do seu entorno com pouca qualidade estética e com poucos atrativos que dessem status de permanência no local. Com uma área total de $12.900 \mathrm{~m}^{2}$, a Praça Nossa Senhora da Luz se tornara um espaço abandonado e marcado pela presença da estação de tratamento de esgoto da Embasa e pela ausência de vegetação ou outros atrativos. Equipamentos em ruínas, famílias de mendigos morando na praça e marginais abordando os passantes, apesar de um módulo policial à vista, era o quadro do 
local nos anos de 1990, conforme a Figura 3. Sua requalificação era uma antiga reivindicação dos moradores do bairro.

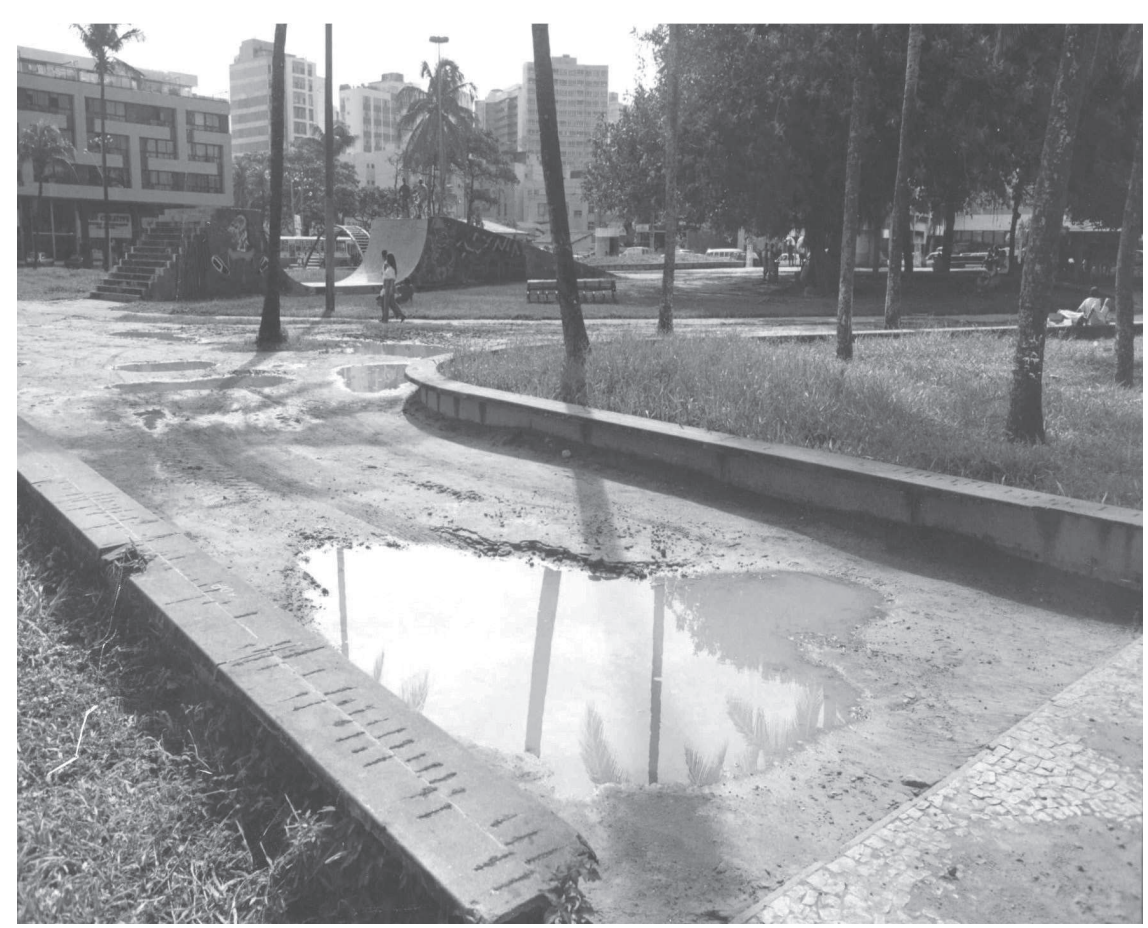

Figura 3: Vista da praça Nossa Senhora da Luz, 1997

Fonte: Jornal A Tarde (1997)

Segundo Neiva (2000), autora e responsável pelo projeto atual de reforma, a praça Nossa Senhora da Luz encontrava-se como um grande espaço vazio, aniquilado pela ausência de um entorno proporcional à sua generosa dimensão, pela forte ação dos ventos que incidem no local devido à proximidade, assim como pela largura da avenida Manoel Dias da Silva, e pela presença da Empresa Baiana de Saneamento e Água - Embasa e sua estação de rebaixamento de esgoto com seus odores, pelo uso indevido que lhe era dado. O notório crescimento urbano do bairro e da cidade seguia seu ritmo indiferente à praça, esquecendo-se dela e esquecendo também do direito à qualidade de vida de seus habitantes. Nesta área, em particular, a Pituba sofria ainda com problemas de drenagem, delinqüência e atividades noturnas de prostituição.

Observou-se, portanto, a necessidade de recuperar a praça Nossa Senhora da Luz, tornando-a própria e devidamente qualificada, definindo um uso correspondente ao bairro. A arquiteta coloca ainda que o intuito foi de resolver problemas, objetivando criar um espaço de troca, de reunião, de festa, de contato e mesmo de contemplação, mas também para que o desenvolvimento urbano se encontrasse, se redescobrisse e fosse liberado sobre este pedaço de terra que se achava um tanto esquecido.

\section{3 - O projeto e reforma da Praça Nossa Senhora da Luz}

A reforma e recuperação da praça Nossa Senhora da Luz propiciou o resgate da praça pela população local, que passou a freqüentar de novo a praça, adotando-a como seu lugar de lazer e contemplação. As mudanças recentes no bairro com a construção de um moderno hotel num dos lados da praça, no início dos anos de 1990, contribuiu para implementar a antiga reivindicação dos moradores locais em relação a um projeto qualificação da praça. Mais recentemente a reforma da avenida ACM ajudou a valorizar essa área do bairro, culminando também com a reforma da lgreja que emoldura, hoje, um dos lados da praça e contribui para o melhoramento dos aspectos estéticos do local. $\bigcirc$ processo em cadeia de recuperação e melhoramento da área 
foi de certa um reflexo do movimento de recuperação e qualificação dos espaços públicos de Salvador nas últimas administrações municipais.

A primeira mudança no projeto da praça foi o conceito da forma, que de retangular passou a ser radial, sendo o seu interior constituído a partir de uma série de círculos concêntricos, alternando áreas verdes com anéis de circulação. Estes círculos são cortados por oito eixos orientados para o centro. Quatro deles, levemente sinuosos e revestidos com granito cinza-escuro, fazem a ligação com os pórticos de entrada e representam a direção dos ventos: nordeste, sudeste, sudoeste e noroeste. Segundo Neiva (2000), os outros eixos, revestidos com porcelanato amarelo, simbolizam os quatro pontos cardeais e possuem formas sinuosas mais acentuadas. A proposta da arquiteta é fazer o desenho da praça parecer uma mandala, um diagrama com vários ciclos e ritmos diferentes que simboliza a essência humana em uma relação harmônica com o universo. Além disso, as indicações espaciais também delineiam o formato de uma grande bússola (ver Figura 1).

A Embasa com seus equipamentos determinava uma utilização específica de uma parte da praça, cuidando da capacitação, distribuição e evacuação da água. Conforme Portela (2001), os caminhos que representam as direções dos ventos levam ao centro da praça, onde está o elemento fundamental: uma fonte luminosa e sonora em forma de estrela de cinco pontas instalada em um tanque inscrito em um círculo de oito metros de diâmetro. Cada um dos jatos de água e luz branca é comandado por um computador e pode ser programado para movimentos seqüenciais rápidos, lentos ou em harmonia com o ritmo de qualquer música.

Antes da reforma do espaço, o centro da praça estava abaixo da cota dos passeios do perímetro e, por isso, apresentava problemas de drenagem. Para permitir a construção da fonte, entretanto, a área teve de ser elevada em dois metros e se transformou em um belvedere de onde é possível contemplar o mar. Outro problema eram os odores desagradáveis provenientes das estações de bombeamento de esgoto, que agora são mascarados por meio de aromatização com essências químicas à base de limão e pela ação natural dos pés de alecrim ali plantados, que desprendem perfume quando recebem o calor do sol.

O paisagismo foi implantado conforme a ordenação da praça, obedecendo a dinâmica dos círculos concêntricos (NEIVA, 2000). Na área compreendida entre o primeiro círculo e o retângulo encontram-se as palmeiras, seguidas pelas árvores de pau-brasil, ipês

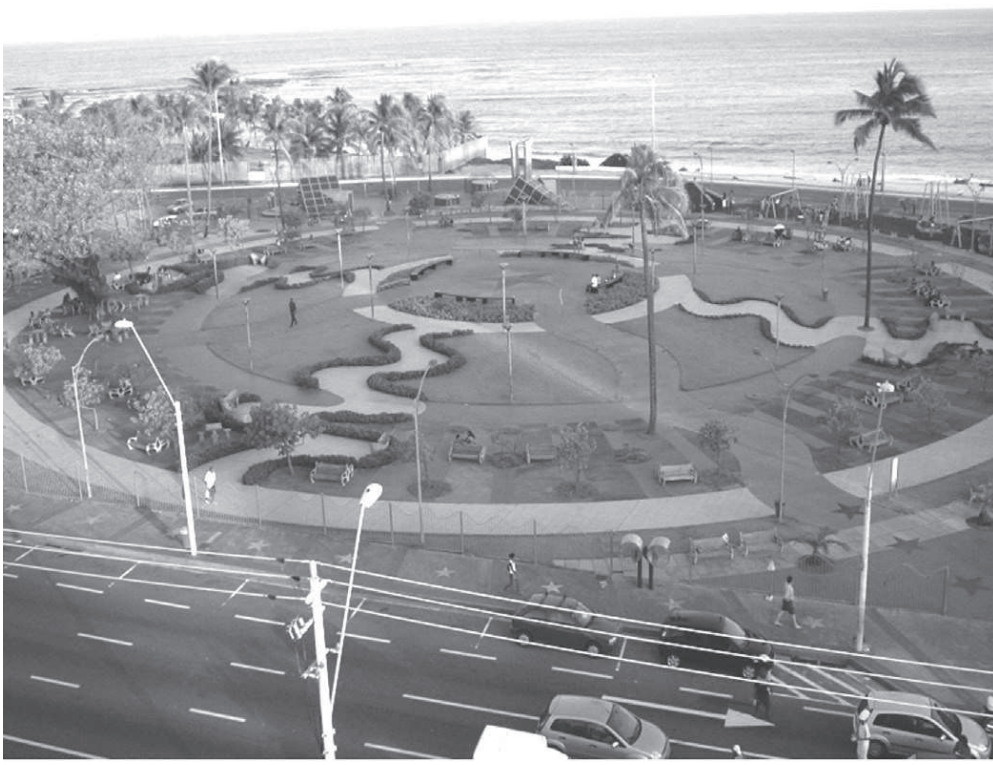
amarelos e quaresmeiras lilases (Figuras 4 e 5). Nos círculos mais próximos ao centro, foram plantados taludes com grama. A arquiteta explica que muitas espécies não resistem ao forte vento do nordeste, predominante na região, mas que a idéia era tentar implantar o número máximo de árvores para garantir sombras, imprescindíveis ao bem-estar dos visitantes.

Os limites da praça foram reforçados por grades onduladas azuis como uma referência ao mar. Segundo a arquiteta, a demarcação da área não elimina o caráter comunitário Figura 4: Aspecto geral da praça Nossa Senhora da Luz Crédito: Foto de Rosa Alencar (maio, 2005) da praça, ao contrário, o reforça, pois protege contra eventuais atos 
de vandalismo e contribui para a conservação do espaço público. Essa medida foi tomada não somente na recuperação dessa praça, mas em várias outras que passaram por reformas recentes na cidade.

O mobiliário, também criação da arquiteta da praça, é composto por poltronas, bancos, namoradeiras, mesas e tamboretes de alumínio fundido e jateado com areia e assentos de madeira. As Figuras 5 e 6 mostram o mobiliário e outros aspectos físicos da praça em uso. A área infantil foi cercada pelas palmeiras, atendendo a uma exigência da prefeitura da cidade, que proibiu a colocação de bancos de areia na praça para evitar a transmissão de doenças às crianças, optando a autora do projeto pelo piso emborrachado.

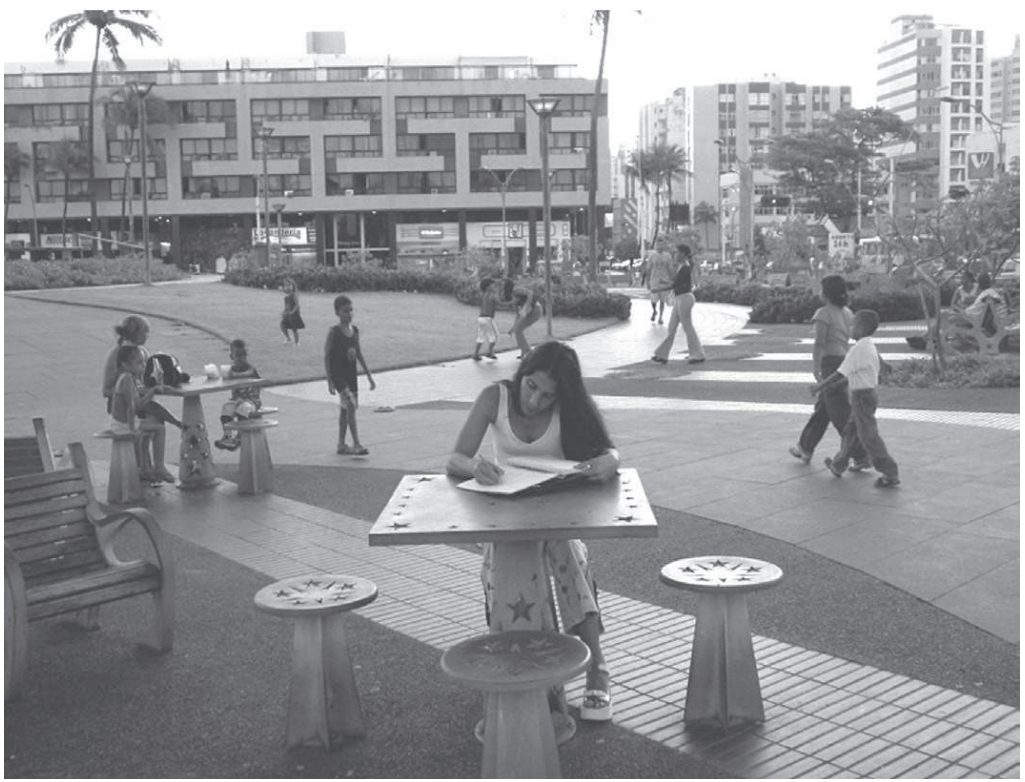

Figura 5: Aspecto do mobiliário, piso e jardim da praça Crédito: Foto de Rosa Alencar (maio, 2005)

A praça, hoje, é freqüentada não só por moradores, mas pelos visitantes do bairro. A resposta ambiental do projeto é satisfatória em vista do crescimento da freqüência e os aspectos físicos e funcionais contemplados pelo projeto possuem um nível de resposta do usuário que faz da praça um local de apropriação por diferentes faixas etárias da população.

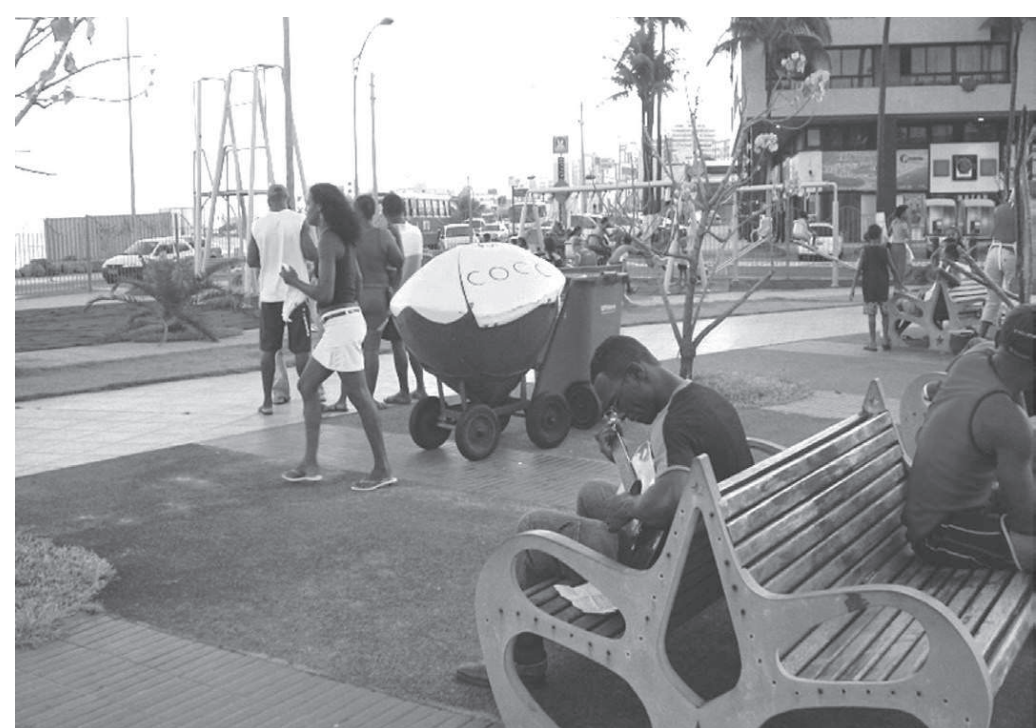

Figuras 6: Aspecto dos bancos e área do parque infantil

Crédito: Foto de Rosa Alencar (maio, 2005)

O projeto mostrou-se importante na recuperação do local como elemento paisagístico de destaque no bairro e o conceito de praça reforçado no projeto através do desenho e da adoção dos elementos de composição fez o espaço recuperar o conceito de lugar do povo porque valoriza 
o cidadão. Ou seja, de espaço abandonado a espaço recuperado, a praça Nossa Senhora da Luz contribui para a Cidade de Salvador "recuperar-se" como espaço urbano.

\section{4 - Considerações finais}

O projeto arquitetônico neste exemplo foi um fator de importante papel na revitalização da praça, pois o retorno da sua utilização pelos moradores e habituais transeuntes demonstra o alto nível de resposta que o projeto proporcionou ao buscar as verdadeiras vocações do espaço. Isso foi conseguindo através do estudo das necessidades locais, além de uma análise do processo de transformação do entorno imediato e das tendências atuais de pensamento dos espaços livres urbanos como algo interligado ao espaço urbano como um todo e não como algo isolado dentro dele.

A compreensão dos espaços livres públicos como fundamentais para o ambiente urbano estende-se na compreensão da manutenção e preservação dos mesmos, além de atender as necessidades da população que os utiliza. Não só a estética desses equipamentos deve ser bem cuidada, eles precisam funcionar adequadamente, pois é uma questão de cidadania ter acesso aos mesmos e é um dever da comunidade e de sua administração mantê-los em ordem. $\bigcirc$ projeto arquitetônico desta praça atrela as transformações para a sua reforma ao relacionamento do espaço com o entorno urbano e a incorporação do conceito de "cidade recuperada" à praça Nossa Senhora da Luz se deve à volta da apropriação do espaço transformando-o em lugar de convívio e de identidade paisagística.

\section{Bibliografia}

ANDRADE, Adriano Bittencourt. Expansão urbana de Salvador: O caso da Pituba. 2003. Tese (Mestrado) - Universidade Federal da Bahia, Salvador-BA, 2003.

BRITO, Cristóvão de C. da Trindade de. Impactos econômicos recentes na economia baiana e a expansão do bairro da Pituba. 1993. Monografia para disciplina Prática e Pesquisa de Campo II - Faculdade de Geografia, Universidade Federal da Bahia, Bahia, 1993.

CUNHA, Rita Dione Araújo. Usos, funções das áreas públicas de uma área central de Florianópolis. 2002. Tese (Doutorado) - Universidade Federal de Santa Catarina, Florianópolis, 2002.

GEHL, Jan; GEMZOE, Lars. Novos espaços urbanos, GG100, 1902-2002. Londres: Academia Real Dinamarquesa de Belas Artes/Escola de Arquitetura, 2000.

MACEDO, Sílvio Soares. Espaços livres. Paisagem e Ambiente - Ensaios. São Paulo: FAUUSP, p. 15-56, 1995.

Introdução a um Quadro do Paisagismo no Brasil. São Paulo: FAUUSP, 1998.

NEIVA, Lucinei Caroso. Praça Nossa Senhora da Luz, projeto executivo e memorial escritivo. Salvador: Fundação Mário Leal Ferreira/Prefeitura da Cidade de Salvador, 2000.

HARDT, L. P. A . Paisagismo em áreas urbanas. Curitiba: UNILIVRE, 1998. 72 p.

PLANDURB. Projeto Pituba. OCEPLAN. Salvador: PLANDURB, 1977. Série Programas e Projetos, n. 1.

PORTELA, Carine. Estrela de luz. Arquitetura \& Urbanismo, ago./set. 2001.

SAMPAIO, Theodoro. Relatório dos estudos e projecto para uma cidade nova (A Cidade Luz). Na Pituba, dos terrenos de propriedade do Sr. Manoel Dias da Silva. Salvador: Imprensa Oficial do Estado, 1919.

TEIXEIRA, Cyd. As grandes doações do 1o governador. Terras do rio Vermelho ao rio Joanes: Conde da Castanheira, Gracia D'Ávila e Senado da Câmara. In: A Grande Salvador. Posse e uso da terra. Projetos urbanísticos integrados. Salvador: Governo do Estadoda Bahia, 1978. 